\title{
Application of Electronic Business in Safe Accident Prevention and Control on Coalface
}

\author{
Guozhi Lu' ${ }^{1}$, Jianquan Tang ${ }^{2}$, Chunhui Yao ${ }^{3}$ and Lei Yang ${ }^{1}$ \\ 1College of Economics and Management, Shandong University of Science \\ and Technology 579 Qianwangang Road Qingdao Economic and \\ Technological Development Zone Shandong, 266510, P.R.China \\ LGZ2050@163.com \\ 2 Institute of Resource and Environment Engineering, Shandong University \\ of Science and Technology579 Qianwangang Road Qingdao Economic and \\ Technological Development Zone Shandong, 266510, P.R.China \\ 3 Geoinfomation Science \& Engineering College, Shandong University of \\ Science and Technology579 Qianwangang Road Qingdao Economic and \\ Technological Development Zone Shandong, 266510, P.R.China
}

\begin{abstract}
In this paper, by analyzing the coal mine safety accident of present stage, the author has come to a conclusion that the safe accidents on coalface accounting for a lot of coal mine safety accident, and has brought forward the cause leading to this phenomenon. Then, through the discussion about "Overlying Strata Movement Law", this author has suggested that Electronic Business can be used for the coal mine to prevent and control safe accident on coalface, and has given out the operating pattern of Electronic Business innovatively. This conclusions are most instructive to Chinese coal mine in managing safe accident on coalface and innovative for application of Electronic Business in coal mine safety.
\end{abstract}

\section{Introduction}

In recent years, the Chinese coal mine casualty accident is very serious, accidents such as roof caving, water inrush, coal bump that caused by extraction (coalface advances) frequently happen. The gas explosions or water inrush accidents causing more than 10 workers to death had appears in the local mine and state-owned coal mines many times, these accidents frequently threaten the safety production of coal mine, at the same time affect the developing image of China mine industry [1].

Please use the following format when citing this chapter:

I.u, G., Tang, J., Yao, C., Yang, I., 2007, in IFIP International Federation for Information Processing, Volume 252, Integration and Innovation Orient to L:-Society Volume 2, eds. Wang, W., (Boston: Springer), pp. 68-74. 
At present, great progress has been made on the safe mining theory of coalface, but since the coal mining is busy and strenuous, safety mining condition is complex and changeful, the new theory and knowledge on coal safety mining can not apply to coal mine safety production practice effectively. In this paper, the operating mechanism of Electronic Business was introduced in detail at first, and coal mine safety exploiting theory was extended and taken as foothold to push Chinese coal mine safety production to a new stage.

\section{Current Situation of China Coal Mine Safety Production and Causes of Accident}

\subsection{Review of history data}

From $2002 \sim 2005$ [2], coal mine safety accident death toll decreases year by year, from 6971 deaths of 2002 dropping down to 5986 people of 2005 . But coal production rises up step by step from 1.45 billion tons of 2002 to 2.16 billion tons of 2005 . In 2002 the death rate of million tons coal is 5.13 , but in 2005 , the death rate of million tons coal comes down to 2.84 . These three indexes can perceive Chinese coal mine safety production is developing to a fine situation.

But in recent years, the increasing of coal mining depth and the changing of geology conditions do not lead to the big change of the occurrence numbers of largescale accident and the super-huge type accident, but one accident death toll rise to some extent. 58 super-huge type safety accidents occurred in 2005, 1739 people died, average accident death toll at every time is about 30 people, but 55 super-huge type accidents occurred in 2002, death 1137 people happened, average about 20 people.

\subsection{Analysis of coal mine safety accidents}

By analyzing the proportion of coal mine safety accident of coal mine from 2002 to 2005 , we can find that roof accident death toll and gas accident death toll accounting for $70 \% \sim 75 \%$ of total death toll, and the following conclusions can be reached.

Firstly, the coal mine safety production circumstance is making a turn for the better day by day;

Secondly, coal mine safety accident population death toll is dropping down, but a super-huge type accident death toll rise to some extent;

Thirdly, the accident caused by people is coming down;

Fourthly, the prevention and control about safe accident on coalface such as the gas explosion, roof caving, water inrush, and coal bump does not make a breakthrough;

Fifthly, the safe accident happened in excavating procedure takes up bigger specific gravity in coal mine safety accident. 


\subsection{Key factor of solving Chinese coal mine safety situation}

By the end of 2005 , more than 24,800 coal mines got Coal mine safety system of state license for the manufacture in China ${ }^{[2]}$, in order to improve the current situation of Chinese coal mine safe production, the following two aspects must be focused:

Firstly, pay close attention to the problem studying of the key and core factors effecting coal mine excavates face safe production, try to find breakthrough from theory and application;

Secondly, strengthen knowledge updating about preventing and control of coal mine safety, explore new approach of technology transfer.

\section{Key Theory of Coal Mine Safety Mining —_ "Overlying Strata Movement Law"}

\subsection{Outline of Overlying Strata Movement Law}

During advancing of coalface or stope, the coal body is mined out, the overburden strata above the stoped out area and the coal body around the face change regularly, this change of the overburden strata above the gob and the coal body around the coal face is called "Overlying Strata Movement Law" [3].

\subsection{Content of Overlying Strata Movement Law}

Firstly, the height of roof caving strata above the gob (immediate roof for short, there is no force transfer between the strata), the first time span of roof caving (the step distance of immediate roof first fall).

The height of rupture roof on the roof fall strata (main roof for short, there is force transfer between the strata), the first time step distance of cliff, period rupture step distance.

The regularly alteration of overlying strata lead to stress's distribution again, form stress elevate area (be called high stress area for short) and stress reduce area (be called low stress area for short) [4];

The range of overlying strata strenuous moving (caving or rupture) when the length of face is definite.

\subsection{Relationship between Overlying Strata Movement Law and safe accident on coal face}

Safe accident on excavate face such as roof accident on the face (roof strides over fall, roof fall and so on ), gas accident (gas density exceed limitation), bump accident, water accident of roof and floor have relation with "Overlying Strata 
Movement Law", it is direct incentive of all kinds of accident[5]. So estimate the rule of strata changing can prevent and control safe accident on Excavate Face.

\subsection{Existing problems on application of "Overlying Strata Movement Law"}

Although "Overlying Strata Movement Law" has stronger directive function to safe accident on the excavate face, but nowadays this theory is not approved and is extended broadly, there is several following aspect:

Coal mine geology condition of China are tremendous difference, the different seam in the same mineral area, the different mining area in the same seam, even the different section in the same mining area may have quit different geology condition, therefore un-discriminatingly applying mechanically identical calculation condition be complete wrong. This is the ultimate reason why "Overlying Strata Movement Law" do not having universal extending.

There are a lot of coal mine in China, and the employee's quality differ at any rate, it is impossible to accept this theory completely and fast. This is the objective reason why "Overlying Strata Movement Law" do not having universal extending.

At present, because of the economy benefit occupies leading factor position in coal mine, facing strenuous production mission and austerity situation of safe production, the manager is tired and do not have any more time and energy to learn modern knowledge and experience. This is the subjective reason why "Overlying Strata Movement Law" do not having universal extending.

\section{Electronic Business Operation of "Forecast and Control the Safety Accident on Coalface"}

\subsection{Advantages of Electronic Business in Extending "Overlying Strata Movement Law"}

There are broad sense and narrow sense about Electronic Business, the broad sense Electronic Business meanings making use of IT to reform traditional business affairs process, communication mode electronically, reach the purpose of data transmission and information communicating [6]. There are several following advantage in using Electronic Business to resolve safe accident problem on excavate face:

Electronic Business can realize distant real time communication, this can solve the real problem of coal mine numerous, distributes broad, have poor transport facilities in China.

Electronic Business can realize online services in time, by calculating the scene data, couples back result, can resolve the problem of the scene personnel is low quality, busy and lacks experience and so on.

Electronic Business can realize great capacity for data memory, can contact the all-direction mining experts, accumulate more practical experience and provide forceful technology hold for preventing and control the coal mine safety accident. 
Coalface

\subsection{Operating pattern of Electronic Business}

The Electronic Business operation pattern of "Forecast and control the safety accident on coal mine excavate face" is commonweal and service and abides by the principle of "serving as guiding, technology support as core, improves coal mine excavate face safety as purpose ".

Manage pattern: commonweal and service;

Manage idea: transfer blind, passive traditional safety manage pattern to initiative, scientific modern safety manage pattern.

Serve object: manager, chief engineer and employees of Chinese coal mine, especially all kinds of technician working at scene.

Manage target: make Chinese coal mine safety information platform, structure Chinese coal mine safety large scale system.

\subsection{Operating framework of Electronic Business}

The operating framework of Electronic Business sees Figure 1.

The portal (Electronic Business website of coal mine safety) provides an Electronic Business platform of forecast and controlling coal mine excavating face safe accident. Through this platform, can announce the new theory about coal mine safety manages, sum up coal mine safety managerial experience, provide the interface to input the scene data, use intelligence computer system to provide situation of safe production, decision suggestion, and scheme of prevent and control accident to every user by the web.

Submit static information means the user submit the inherence information of a fixed face. This part information is: fundamental parameter information of face (includes the trend long of face, the incline long of face, obliquity, relative coordinate etc.); borehole post shape picture of the area where face located (includes: anti-press intensity, anti-pull intensity and so on); contour of seam bottom; plane disposal chart of face. Trough this information can draw the outline of relative stratum, geology condition and space-time relation.

The static state data is to describe the geology form of face location mainly, it is that all basis of accidents forecast and controlling.

Submit dynamic data since stratum geologic structure is multifarious, even if different section of the same stope there is very distant difference condition in geology also. Because of the gap of drilling and inaccuracy of stratum geology parametric, the Overlying Strata Movement Law may change a lot in the excavate face push forward process. Therefore must use relative instrument to observe and measure the press of roadway and face incessantly, calculate in time, adjust relative parameter of the model [7], to make the mathematic model of Overlying Strata Movement Law fit actual model step by step, achieve the purpose of provide reliable decision support information to the scene.

Backstage information platform the information platform behind the website has two composition parts mainly: the first part is decision support intelligence analysis system of coal mine safety and high-effect production, this system can provide automatic information analysis on the base of given information, give 
reasonable suggestion about some problem in the mining process; the second part is the coal mine expert serves system, the simulation result made by computer can not be the ultimate basis, the result should feed back to expert regiment, and the expert regiment make the finally decision to ascertain accuracy of decision information.

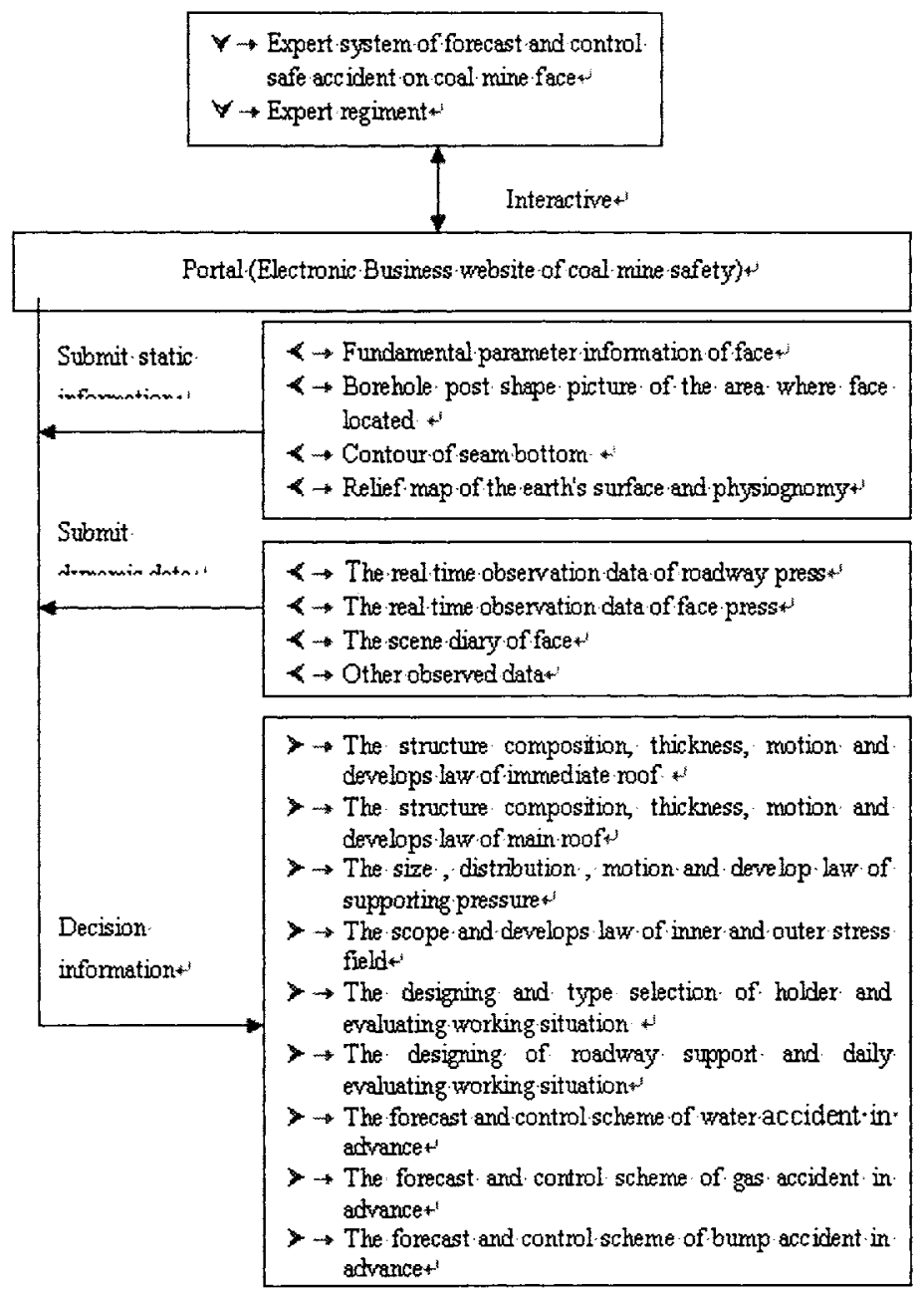

Figure 1 The Electronic Business structure in Safe Accident Prevention and Control on Coalface

Decision-making supports information to forecasting and control the safe accident on excavate face, the Electronic Business platform should provides scene worker some parameters, such as the structure composition, thickness, motion and develop law of immediate roof; the structure composition, thickness, motion and develop law of main roof; the size, distribution, motion and develop law of support 
Coalface

press; the scope and develops law of inner and outer stress field; the designing and type selection of holder and evaluating working situation; the designing of roadway support and daily evaluating working situation; the forecast and control scheme of water accident in advance; the forecast and control scheme of gas accident in advance; the forecast and control scheme of bump accident in advance, etc.

\section{Conclusions and Expectations}

Safety and high-effect production of coal mine is a great event being to concern Chinese economy, politics, Electronic Business is a new and developing commerce operating pattern, it has practical significant to combine these two aspects.

The "Overlying Strata Movement Law" has guiding significance to prevent and control safe accident on excavate face, and the Electronic Business pattern mentioned in this text has feasibility and maneuverability, this pattern has vast application prospect and extensibility value.

\section{References}

1. W.J. Zhang, Z.Q. Song, "Present Situation and Direction of the Study on Severe Disasters in Coalmines", Journal of Shandong University of Science and Technology, No.1, (2006), pp. 5-8.

2. "The Eleventh Five Plan For of Coalmine Safety Science and Technology", (State Administrator of Work Safety, State Administrator of coal Mine Safety, BeiJing,2006), pp. 13 .

3. Z.Q. Song, The Information Of Strata In Severe Disasters In Coalmines, The Press Of Coal Industry, BeiJing, 2003, p. 12.

4. Z.Q. Song, G.Z. Lu, "A New Algorithm for Calculating the Distribution of Face Abutment Pressure", Journal of Shandong University of Science and Technology, No.1, (2006), pp. 1-4.

5. Z.Q. Song, G.Z. Lu, "Forecast and Prevention of Rockburst for Colliery and Its Motivity Information System", Journal of Shandong University of Science and Technology, No.4, (2006), pp. 1-4.

6. G.Z. Lu, The New native of all kinds of accident. Edition Of The E-Business Conspectus, (The Press Of Peking University, BeiJing, 2005), p. 3.

7. G.Z. Lu, "Study of Combined Observation Scheme about Coal Mine Stress", Rock and Mechanics, 2006(Supp), pp. 319-321. 